\title{
Macrosocial Determinants of Social Integration: Social Class and Area Effect
}

\author{
ENRIQUE GRACIA, FERNANDO GARCÍA and GONZALO MUSITU \\ Facultad de Psicología, Universitat de València, Avda. Blasco Ibáñez 21, 46010 Valencia, \\ España/Spain
}

\begin{abstract}
Theory and research on social support have paid little attention to the existence of important macrosocial variables determining level and content of social relationships. This study examines variations in social integration as a function of social class and residential area characteristics. Results for 234 subjects living in high and low risk neighbourhoods indicated that differences between higher and lower social class groups follow different patterns in different residential areas. Also, same social class position appeared to have different significance as a function of residential area characteristics. The levels of three social integration measures-community integration and satisfaction, community association and participation, and contribution in community organizations-were significantly higher for lower class in low risk neighbourhoods than in high risk ones. However, significant differences were found in only one measure for higher social class groups, with higher levels of community association and participation in high risk neighbourhoods than in low risk ones. The discussion examines a 'social impoverishment' hypothesis for high risk environments, and proposes possible protective factors for higher status residents. Relations between formal and informal sources of support, and implications for social intervention strategies are also considered.
\end{abstract}

Key words: macrosocial determinants; social support; social integration; community support; social class; area effect; social impoverishment

A major shortcoming in the existing theory and research has been the lack of attention paid to the study of social support as a dependent variable (Broadhead, Berton, James, Wagner, and Schoenbach, 1983; Hays and Oxley, 1986; House, Umberson and Landis, 1988). The origins of social support research in the health sciences and its main focus on health as a dependent variable accounts primarily for this characteristic of the field. Since the early 1970 s social support research has produced a vast amount of data documenting the positive association between supportive relationships and health and psychological well-being, and analysing the mechanisms through which this

This research was supported by a grant from the EEC Human Capital and Mobility programme to Enrique Gracia (ERBCHBICT930280), and by the Ministry of Education and Science of Spain to Gonzalo Musitu (grant PB90-0428).

We wish to thank Julie Bullen for her helpful comments on an earlier draft of this manuscript. 
association operates. However, limited research effort has been directed to examining the factors that determine the development, structure and functioning of these relationships (Heller and Swindle, 1983; Gottlieb, 1985; Hays and Oxley, 1986; Eckenrode and Wethington, 1990). As House et al. (1988) have pointed out,

Researchers and theorists have extensively studied social relationships as independent, intervening and moderating variables that may affect psychosocial stress or health or the relations between stress and health. Yet almost no attention has been paid to social integration, networks or supports as dependent variables (p. 308, italics in original).

Variables determining the development, structure, and functioning of social relationships need to be analysed at different levels - personal, situational, social, and ecological (Broadhead et al., 1983; Hays and Oxley, 1986; House et al., 1988; Vaux, 1990). Social scientists, and in particular social psychologists, have concentrated their research efforts principally on the more psychological and microsocial level (House et al., 1988). Empirical associations have been found between support processes and variables such as personality (Jones, 1985; Stokes, 1985; DePaulo, Dull, Greenberg, and Swain, 1989; Newcomb, 1990), social skills (Sarason, Sarason, Hacker, and Bashman, 1985; Cohen, Sherrod, and Clark, 1986), network orientation and help-seeking beliefs (Eckenrode, 1983; Vaux, Burda, and Stewart, 1986), and stressor characteristics (Hobfoll and London, 1986; Pearlin and McCall, 1990). However, research on social support has largely ignored 'the existence of important macrosocial determinants of levels and content of social relationships' (House et al., 1988; p. 310). Social status and social roles, such as gender, race/ethnicity, and socioeconomic position, as well as social ecological factors, such as habitat (i.e. rural versus urban) and patterns of community and housing, are among such macrosocial determinants.

A sizeable number of researchers have stressed the importance of considering more social structural variables in order to understand how structures and functions of support are determined (Broadhead, et al., 1983; Pearlin, 1985; Hays and Oxley, 1986; House et al., 1988; Vaux 1988; Eckenrode and Wethington, 1990; Brand and Hirsh, 1990). For example, as posited by Pearlin (1985; p. 59) '... support, itself intrinsically social and interactional, takes place within larger structured social and cultural contexts. These contexts, in turn, help to shape the character and outcomes of support'. Also, more recently, Eckenrode and Wethington (1990; p. 99) have emphasized the need to consider the broader social context as an important determinant of social support mobilization: 'Social-structure position and social-group membership of this sort (gender, age, life-cycle stage, ethnicity, and social status) shape barriers and opportunities for social support mobilization'. However, despite this emphasis, as Brand and Hirsh (1990; p. 159) observe, 'only a handful of relevant studies have been conducted'.

According to House et al. (1988), the impact of macrosocial structures on processes of social integration and support can be illuminated by several kinds of research. First, examining how structures and processes of social relationships vary across groups of individuals in different structural positions in society, such as class, age, and gender. Second, examining variations in structures and processes of social relationships across different organizational units of society, such as different communities (urban versus rural), formal organizations, and residential areas. And, finally, examining the effects of planned or unplanned changes in macrosocial structures of society, such as changes in public policy. 
Following this framework, the study reported in this article aims to bring together the first two kinds of research proposed by House et al. (1988) by examining variables at each of these levels. Thus, socioeconomic position of individuals, and level of risk of residential area were selected to be explored as determinants of variations in social integration. These variables are theoretically relevant in the context of a 'social impoverishment' hypothesis (Garbarino and Sherman, 1980). According to this hypothesis, a high risk environment impoverishes the social life of those living within it, independently of socioeconomic variables.

Research on social class and social relationships has examined the extent to which a wide range of relationships - family, friendship, neighbours, leisure groups, voluntary associations - show different characteristics as a function of socioeconomic position (see Argyle, 1994, for a recent revision). Social class differences in social relationships and social support have been found in a number of surveys (Laumann, 1973; Young and Willmott, 1973; Veroff, Douvan, and Kulka, 1981; Fisher, 1982; MORI, 1982; Willmott, 1987); in studies including class measures (Bell, Leroy, and Stephenson, 1982; Thoits, 1982; Belle, 1983; Eckenrode, 1983; Hanson and Ostergren, 1987; Oakley and Rajan, 1991); and cross-cultural research (Cochran, Gunnarson, Grabe, and Lewis, 1990). In general, the picture that emerges from these studies indicates that subjects with lower levels of education and income have smaller networks, lower availability and quality of both material and emotional support, and lower social participation and involvement in organizations.

Research examining variations in structures and processes of social relationships as a function of the nature of the community in which individuals live has focused on rural-urban differences, as well as on differences between residential areas, neighbourhoods or other spatially defined areas of the city. For example, Fisher (1982), reported differences in composition and structure of social networks between urban and rural communities, with more dense and kin-based networks in rural areas, and less dense networks, including more non-relatives, in urban areas. Within urban areas, for example, in a survey with a probabilistic sample of all residential areas of Baltimore, Crenson (1983) found that the neighbourhood environment in which a person lives can be as important for the sense of neighbourhood identity as the individual resident's own characteristics, such as social class or race. Also, research comparing council states and inner areas with middle class suburbs, suggest that inner areas are more often characterized by social isolation, lack of community sense, and conflict (Harrison, 1983; Willmott, 1986).

Of particular interest for the present study are studies that have observed 'area effects' or 'community effects' (Bronfenbrenner, Moen, and Garbarino, 1984) in other domains. For example, Rutter, Cox, Tupling, Berger, and Youle (1975), controlling for ethnicity, class, and demographic factors, observed higher rates of psychiatric disorder in urban versus rural environments. Furthermore, Rutter and Quinton (1977), comparing rates of psychiatric disorder in different neighbourhoods, found that, irrespective of their background characteristics, persons living in a vulnerable area had a higher risk of psychiatric disorder. Research on infant mortality rates and on child maltreatment also indicate that local community factors can work to attenuate or to increase the negative effects of poverty on families (Garbarino and Kostelny, 1993). For example, research on child abuse found that a high risk neighbourhood represented a socially impoverished human ecology, even though it was socioeconomically and demographically equivalent to a low-risk area (Garbarino and Sherman, 1980). 
This research illustrates, in Rutter's terms, effects that are to some extent ecological as well as individual.

Drawing from these ideas, this study aims to explore the independent and interactive influence of socioeconomic status and the level of risk of the residential area as determinants of levels of social integration. The research examined above suggest that the association between social class and social integration may be modulated by local community factors, such as level of risk. According to a 'social impoverishment' hypothesis, the relationship between low socioeconomic status and poor social integration would be predicted to be stronger in a high risk environment than in a low risk environment. This study aims to test this hypothesis by drawing comparisons of social integration, both intra-class and across-class, in neighbourhoods with different levels of risk. Our main interest is, therefore, to examine the interaction between class and level of risk, rather than purely overall levels of social integration on different neighbourhoods.

\section{METHOD}

\section{Participants}

The sample consisted of 234 participants living in two urban residential areas with different levels of risk. These residential areas were defined as high risk and low risk neighbourhoods. The high risk neighbourhood selected was one designated as 'priority social action area' by the Local Government Department of Social Services (Valencia City, Spain) according to the following criteria:

- Poor quality infrastructure and amenities.

- Lack of resources and services in general and, in particular, social resources and cultural activities.

- Low level of education and high level of failure in school.

- Fundamental social problems: unemployment, delinquency, poverty, family violence, and drug addiction.

- Problems associated with youth, such as difficulties incorporating young people into the job market, lack of leisure opportunities, and low expectations.

- High prevalence of working class.

The high risk area selected also met the criteria proposed by Keller (1968), according to which a high risk residential area is sharply defined and widely know. In our study this neighbourhood had captured the attention of politicians, mass media (TV, press, and radio), and had local notoriety.

A low risk neighbourhood was selected according to the following criteria:

- No high risk area characteristics.

- Not middle class suburbs, or affluent areas.

- Similar number of inhabitants to the high risk area.

- Geographically close to the high risk area (both residential areas in the same city, although without physical proximity).

The participants had to meet the following criteria to be included in the study: married, with children, living at least 2 years in the neighbourhood, and not belonging to an ethnic minority group (this allowed the control of ethnicity/race, and residential 
mobility). The Census was used to identify families in both neighbourhoods meeting those characteristics. The total number of families detected in the high risk area was 618 , of which a sample of 150 was selected randomly for use in the study. Out of this sample, 117 people agreed to respond to the questionnaires at home in the high risk area. This number of participants was matched in the low risk neighbourhood. Respondents were 42 per cent male and 58 per cent female.

\section{Measures}

As Veiel and Baumann (1992) note, the term social support as it is currently used, commonly implies an abstract characteristic of persons, behaviours, relationships, or social systems. In that sense, social support has been said to represent a metaconcept (Vaux et al., 1986) lacking specificity and definition (Barrera, 1986), rather than a definable and measurable entity. According to Laireiter and Baumann (1992), only multidimensional taxonomies seem adequate for solving the conceptual problems of social support. For example, House et al. (1988) argue for a theoretical subdivision into social integration, social networks, and relational content, which would represent distinct concepts that operate in different ways and have to be measured separately. Vaux (1992) proposes a taxonomy that substitutes the term social support by three constructs: 'network resources', 'social support appraisal', and 'social support behaviour'. Also, Laireiter and Baumann (1992) have proposed a taxonomy that comprises five components: (1) social integration (social embeddedness); (2) potential and actual supporters (support network, network resources); (3) support as a characteristic of the climate of social aggregate and social environments (supportive climate, supportive environment); (4) received and enacted support; and (5) the perception of being supported.

This study aims to analyse variations on social integration measures as a function of social class and the level of risk of the residential area. Following Laireiter and Baumann's taxonomy (1992), the construct of social integration refers to the participation and involvement of a person in his or her social life in the community and society. According to these authors, the criteria for defining a person's social integration are, among others: 'being in regular contact with neighbours', 'having friends or relatives in the neighbourhood', and 'membership of social groups'.

In the present study, to measure social integration a self-report questionnaire based on the definition and dimensions of community support proposed by Lin, Dumin, and Woelfel (1986) was constructed. According to Lin et al., measures of community support represents the outermost layers of social relations, and allow us to 'capture integration into the larger social structure - a sense of belongingness' (p. 155). The concept of community support would correspond with what has been called 'weak ties' (Granovetter, 1973), a concept that covers a wide range of potential supporters who lie beyond the primary network of family and close friends (Adelman, Parks, and Albrecht, 1987).

The 33-item questionnaire includes four scales tapping different dimensions of social integration (questions refer to the community in which participants live):

(1) Community, integration and satisfaction: This 10-item scale measures social interactions with neighbours and members of the community, and satisfaction with social relations in the neighbourhood and with the community as a whole. The alpha coefficients for this scale was 0.82 . 
(2) Community association and participation: This scale consists of 10 items that measure individual membership and participation in voluntary organizations - such as church, clubs, civic groups, unions, etc. The internal consistency coefficient for this scale was 0.78 .

(3) Contribution to community organizations: This 5-item scale measures the degree of personal involvement in voluntary organizations. This scale had an alpha coefficient of 0.69 .

(4) Community resources of social support: This 8-item scale measures actual or potential use of formal and organized services in case of need, such as local social services agencies, drug and alcohol rehabilitative services, community mental health centres, counselling centres, church, etc. The alpha coefficient for this scale was 0.62 .

Within the two samples selected, from high and low risk areas, subjects social class scores were obtained from occupation and level of education measures. To obtain social class scores from occupation and level of education, the Index of Status Characteristics (ISC), developed in the Department of Psychology of Complutense University (Madrid) was used. This method divides occupation into six categories, ranging from non-skilled workers to executive posts in companies and public administration (scores range from 1 to 6). Education is divided into six categories from no formal qualification to university degree level (scores range from 0 to 5). As all subjects were married couples, social class scores were calculated for households, rather than individually. This score was obtained from the ISC using the following formula: scores for occupation and education were calculated for each member of the couple. The sum of both scores for occupation were multiplied by four, and the sum of the two scores for education by five. These two products were added and the result divided by 10 . In Spain, prefixed categories of socioeconomic status are not commonly used. The method used in the present study produced a continuous socioeconomic measure that enabled the comparison of means. For the statistical analyses, groups based on social class scores were decided to be obtained by empirical procedures.

\section{RESULTS}

To maximize the power of the design, social class groups were empirically established using cluster analysis in order to maximize intragroup similarity and intergroup differentiation. The cluster analysis ( $K$-means method) was applied to the total sample using measures of occupation and level of education. By this procedure two social class groups were obtained. Both groups were significantly different in social class scores $(F$ $=599.497 ; p<0.001)$. The mean for the first cluster-Low Social Class-was 3.07, and for the second - High Social Class — was 7.09 (the 'low' and 'high' social class groups do not correspond to a prefixed classification of socioeconomic groups, they are labels applied to the groups obtained empirically by the cluster analysis).

Table 1 shows the distribution of social class groups in high and low risk neighbourhoods. The number of subjects for each of the four groups is different. To examine differences between the four groups in each of the social integration measures, a $2 \times 2$ design with balanced groups was chosen. Balanced designs allow the estimates of effects of factors and their interactions to be orthogonal (Wilkinson, 1986). The group 
Table 1. Distribution of social class by residential area

\begin{tabular}{lccc}
\hline Social class & \multicolumn{3}{c}{ Residential area } \\
\cline { 2 - 4 } & High Risk & Low Risk & Total \\
\hline Low & 97 & 48 & 145 \\
High & 20 & 69 & 89 \\
Total & 117 & 117 & 234 \\
\hline
\end{tabular}

of high social class living in a high risk neighbourhood had the lowest number of subjects $(n=20)$. Therefore, to balance the number of participants in the four groups, 20 subjects were randomly selected in each of the other groups.

\section{Community integration and satisfaction}

A $2 \times 2$ factorial design was applied, assigning the first measure of social integration-Community Integration and Satisfaction - as the dependent variable and Social Class and Residential Area as the independent. No gender differences were found in this dimension of social integration, or in the others.

A significant main effect for the variable residential area $(F=13.019 ; p=0.001)$ was found. In addition, the interaction between class and residential area $(F=9.321 ; p=$ 0.003 ) was significant. To control for the overall comparison error rate of multiple hypotheses we used the Bonferroni procedure. This method is extremely powerful, especially for testing a relatively small number of hypotheses (Wilkinson, 1986). Possible differences between the four groups were tested in three contrasts (Fig. 1). According to the Bonferroni procedure, for the overall rate to be alpha, each of $K$ comparisons has to be at alpha/ $K$ (Wilkinson, 1986). In our case to obtain an overall

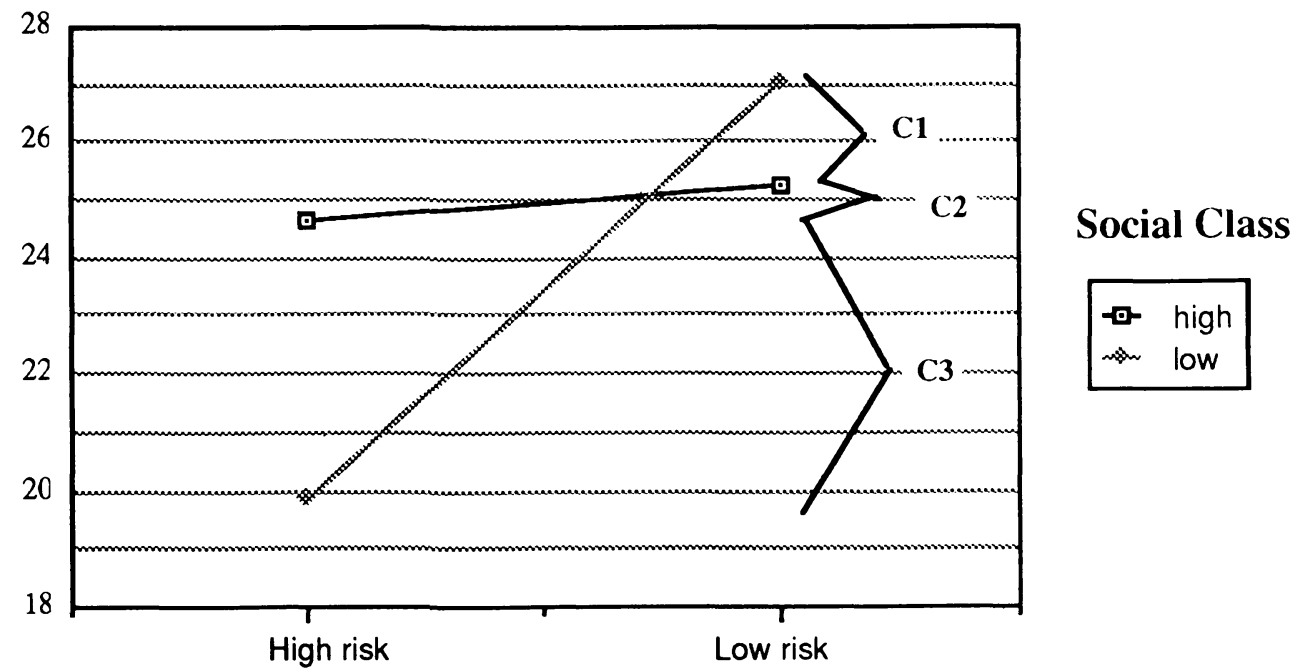

Residential area

Figure 1. Community integration and satisfaction. Contrasts between groups. 
protection level of 0.05 for three comparisons we used a critical level of 0.017 instead of 0.05 .

In the high risk neighbourhood, the level of community integration and satisfaction was significantly higher (contrast 3: $F=9.861 ; p=0.002$ ) for the high social class group than for the low social class group. However, no differences between low and high social class groups were found in the low risk area (contrast 1).

For low social class groups, the level of community integration and satisfaction was lower in the high risk neighbourhood than in the low risk area. Note that the distance between the means of these two groups is larger than those compared in contrast 3 , and therefore it can be assumed that the differences are significant.

For high social class groups, there was no variation in community integration and satisfaction as a function of residential area (contrast 2).

\section{Community association and participation}

Following the same procedure, we analysed possible variations in Community Association and Participation as a function of social class and residential area. No main effects were found, only the interaction between class and residential area was significant $(F=28.473 ; p<0.001)$. Again, differences between the four groups were tested with three contrasts (Fig. 2).

In the high risk neighbourhood, the level of community association and participation was higher in the high social class group than in the low social class group. Interestingly, when compared in low risk areas, the differences between social class groups are inverted, with higher levels of community association and participation in the low social class group than in the high social class group (Fig. 2).

For high social class groups there was a significant variation in levels of community association and participation (contrast $2: F=11.644 ; p=0.001$ ) as a function of

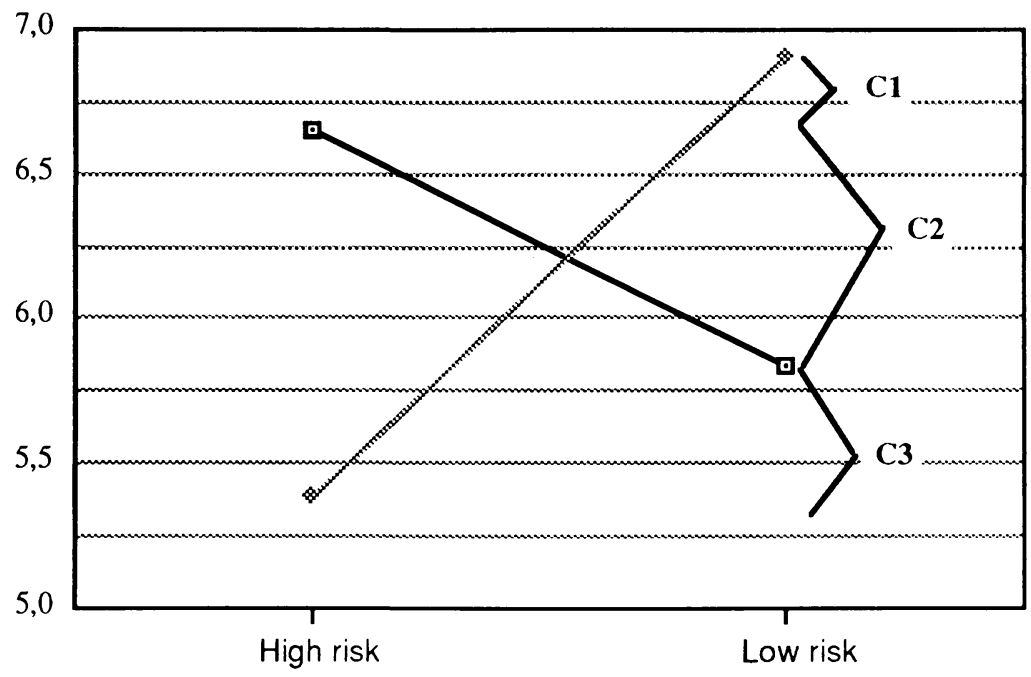

Social Class

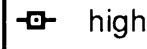

ske. low

\section{Residential Area}

Figure 2. Community association and participation. Contrasts between groups. 
residential area, with higher levels in the high risk neighbourhood than in the low risk neighbourhood (Fig. 2). For low social class groups the pattern was inverted, with lower levels of community association and participation in the high risk neighbourhood than in the low risk neighbourhood. Note that the distance between the means of these two groups was larger than in the groups compared in contrast 2.

\section{Contribution in community organizations}

A significant main effect for the variable residential area $(F=8.117 ; p=0.006)$ was obtained in the 2-way ANOVA. The interaction between class and residential area was also significant $(F=27.866 ; p<0.001)$.

In the high risk neighbourhood, the level of contribution in community organizations was significantly higher (contrast $2: F=14.086, p<0.001$ ) for the high social class group than for the low social class group. Also, in the low risk neighbourhood there were significant differences between social class groups (contrast 1: $F=13.784$, $p<0.001$ ), although again the direction is inverted, with higher levels of contribution in community organizations in the low social class group than in the high social class group (Fig. 3).

For low social class groups, the level of contribution in community organizations was lower in the high risk neighbourhood than in the low risk area. Note that the distance between the means of these groups is larger than those compared in contrasts 1 and 2 (Fig. 3). For high social class groups there was no significant variation in this variable as a function of residential area (contrast 3$)$.

\section{Community resources of social support}

Finally, with respect to the last measure of social integration, Community Resources of Social Support, no significant differences were found.

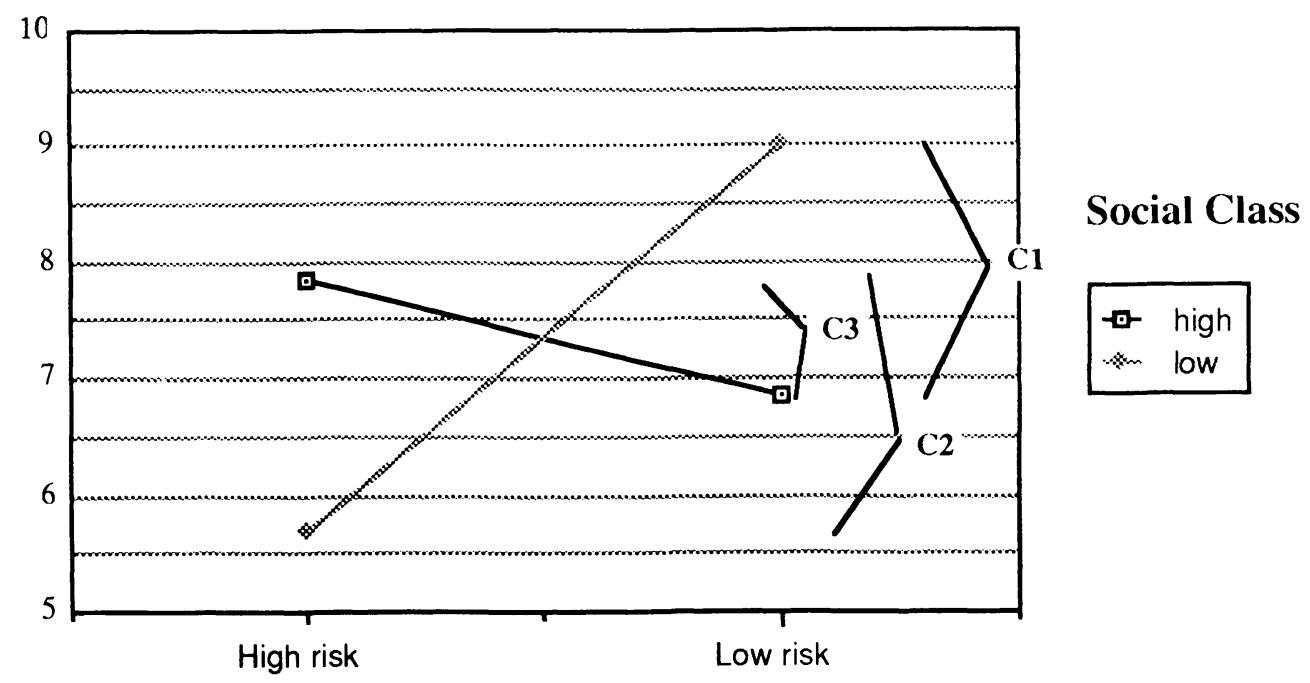

\section{Residential Area}

Figure 3. Contribution in community organizations. Contrasts between groups. 


\section{DISCUSSION}

The study found that the same social class position appeared to have a different significance as a function of the residential area. Significant differences between low social class groups living in high and low risk neighbourhoods have been found in three social integration measures. In only one measure (community association and participation) were differences between high social class subjects living in different neighbourhoods observed. This study has also shown that differences between low and high social class groups follow different patterns in different residential areas. These findings support the need for a more ecological approach in order to understand how structures and processes of support are determined (Vaux, 1990).

From our data a consistent pattern has emerged in which lower class people living in high risk neighbourhoods may be characterized as socially impoverished in comparison to the same social class participants living in a low risk neighbourhood. In other words, levels of community integration and satisfaction, community association and participation, and contribution in community organizations, are significantly higher for lower class in low risk environments than in high risk ones. These results appear to support a social impoverishment hypothesis (Garbarino and Sherman, 1980), according to which these high risk environments reduce the quality of social life for the people who occupy them (however, our findings are correlational and cannot be interpreted as indicating the existence of causal relationships). Although this corresponds with the results for low social class subjects living in a high risk neighbourhood, the same cannot be applied to higher social class subjects living in the same neighbourhood. Certainly, if we consider that these high risk neighbourhoods have predominantly low social class populations, then the social impoverishment hypothesis would be, in general, correct, in the sense that these neighbourhoods are socially impoverished ones. Although, perhaps, it would be more precise to state that these high risk environments impoverish the social life of those already disadvantaged.

How to explain then, the lack of a more general 'area effect', affecting also higher social class residents. That is, a more collective impoverishment that affects all residents, including the better off, as Pacione (1990) predicts. We propose the following possibilities.

In these 'high risk neighbourhoods' economic and social problems tend to be compounded and intensified. According to Anderson's analysis (1990), in these high risk areas, crime, drugs, and general antisocial behaviour serve as social forces that underscore status lines drawn within the community. As a consequence, fear and distrust increase, and many of the better off would probably like to get as far away as they could. If they can't achieve this by moving physically, they might try to accomplish it socially, by distancing themselves from others who don't meet their standards, building their own networks against which they are likely to define their level of social integration. The higher levels of community integration and satisfaction found for this group may then refer to these networks rather than to the community as a whole.

In addition, middle class people have been considered more enthusiastic joiners, and more involved and active in their local community affairs, through more extensive and expanded formal association ties (Willmott, 1987). High risk neighbourhoods certainly suffer from more problems than low risk ones. Therefore, a possible interpretation for our data is that high status residents are more likely to respond to the problems of high 
risk neighbourhoods than low status residents, which would be consistent with our findings of higher levels of community association and participation and involvement in community organizations for high status residents in high risk areas. As Crenson (1983) suggests, this difference would be explained by the advantages for the high status conferred by higher incomes, higher levels of education (resulting in more skills), and more prestigious occupations (meaning more social connections). That is, these high status residents are exposed to the problems that come from living in a socially disadvantaged community, but they have personal resources that increase their ability to respond to these problems in an environment where these resources are in short supply. In less disadvantaged communities, however, surrounded by other people with similar resources the value of those advantages would not be so apparent. This may explain the lower levels of community association and participation found for high status residents in low risk neighbourhoods. Similarly, Crenson's survey data showed that not only high status people generally tend to exceed their low status neighbours when it comes to unofficial activism but that this tendency is more consistent and pronounced within the relative poor neighbourhoods than in the rich ones (Crenson, 1983).

However, the pattern of the high social class group having higher levels of association and involvement in community organizations changes when we consider the low risk area. In the low risk area we found that low social class residents were more enthusiastic joiners and more involved in community organizations than high social class residents. A possible explanation for this finding, drawn again from Crenson's analysis, is that the level of involvement in organizational activities for high status people depends on the intensification of the motives for it. 'Confronted by an uncongenial and possibly hostile locale, therefore, the high status residents of poorly integrated neighbourhoods have specially powerful incentives to organize for the defense of their interests' (Crenson, 1983; p. 215). Therefore, in high risk areas high status residents may become specially active, but such motivation may dissipate in a low risk environment. For low status people living in high risk areas the level of involvement in community organizations may remain low because these groups may not represent their interests. Thus, low status people may be less involved in community organizations in high risk areas than in low risk ones. Crenson's survey similarly showed that high status respondents were more likely to become members of community groups in the factionalized neighbourhoods than in the more peaceful areas, the opposite being true for low status residents. On the other hand, motives and responses for low status residents may be different from those of high status residents. For low status people, involvement in community organizations may also be determined by their higher needs and lack of resources. The concept of 'free from drain' (Collins and Pancoast, 1976) offers another possible explanation of low status residents withdrawal from community organization in high risk areas, and their higher level of involvement in low risk ones (see Garbarino and Sherman, 1980). The concept of 'free from drain' was used by Collins and Pancoast (1976) to describe people who can afford to give to and to share with neighbours because the balance of needs and resources favour the latter. According to Garbarino and Sherman's analysis (1980), socially impoverished environments lack people who are 'free from drain' and, therefore, tend to operate on a 'scarcity' economy when it comes to neighbouring. In these high risk areas those who are in need have to compete for scarce social resources in a neighbourhood context dominated by other people in need. In this environment fear of exploitation (getting as much as 
possible, giving as little as possible) and an attitude of ambivalence about neighbourly exchanges may develop. However, in a low risk environment, generally including people who are more 'free from drain', people can afford to become involved in exchanges without fear of exploitation (Garbarino and Sherman, 1980). Therefore, low status people may benefit more from getting involved in community organizations in such an environment where exchanges of resources is freer because their needs are greater and their resources less than high status residents.

These hypotheses, however, cannot be tested within our data set. The present study is of an exploratory nature and limited in its measures. Further research, in which issues such as class homogeneity, cross-class relationships, and class patterns of different social relationships are considered as well, will be needed to address these theoretical questions in more detail.

The fact that no differences have been found in the use of formal and organized services of support as a function of class and residential area deserves further consideration. As Abrams, Abrams, Humphrey, and Snaith (1989) suggest, it can be argued that low social class people, because of their economic and social circumstances should more readily ask for or receive help from official and voluntary welfare agencies. However, like Abrams et al. (1989), we did not find it to be so. A possible interpretation for this lies in the fact that support given by formal and organized services of help usually lacks the dimension of reciprocity (with the exception of self-help groups), and tends to be based on the use of authority. Also, having to request help from formal systems of support may constitute a threat to the self-esteem in the sense that it involves a public admission of failure and inferiority (Fisher et al., 1982). As Tiejten (1980) has pointed out, when people need support and assistance, they look to sources that will increase their feelings of competence and control over their own lives. Friends, relatives, and neighbours are relationships based on esteem rather than authority, and on reciprocity rather than on unidirectional aid, and are more likely to enhance feelings of competence and control over one's own life than support from many formal support systems. This raises the question of the extent to which formal systems of support can meaningfully substitute for informal support networks, and support a notion of social service provision that combines the efforts of the professional service providers with those of informal helpers in a more planned and articulated way (Froland, Pancoast, Chapman, and Kimboko, 1981).

Finally, some implications for intervention strategies can be drawn from this study. As the social impoverishment for those more disadvantaged has become apparent in high risk environments, the results obtained in the present study would support the view that policies of 'positive discrimination' in favour of deprived and disadvantaged cities or neighbourhoods are crucial in social intervention strategies (Knox, 1989). As Pacione (1990) has stressed, area-based policies of positive discrimination can provide benefits which enable people to improve some aspects of their quality of life. These policies have the following implicit assumptions as summarized by Knox (1989; p. 33): (1) identifiable areas do in fact exist where a significantly high proportion of the population is disadvantaged (by whatever criteria); (2) disadvantaged people and households are concentrated into such areas; and (3) because of a neighbourhood or multiplier effect, the same resources can alleviate more problems when the target population is geographically concentrated than when it is scattered.

This study has illustrated how levels of community integration and satisfaction, community association and participation, and contribution in community organiz- 
ations are determined by class and residential area characteristics, and how these variables have interactive effects. Determinants of social integration and support are, however, multiple and operate at different levels-personal, situational, social, and ecological. Research has traditionally focused on one or another level, and rarely has considered them simultaneously. To test hypotheses regarding multiple determinants and their interactive effects, an integrative and multivariate approach, in which variables working at different levels are incorporated in the same research design, will be needed in future research.

\section{REFERENCES}

Abrams, P., Abrams, S., Humphrey, R. and Snaith, R. (1989). Neighbourhood Care and Social Policy, HMSO, London.

Adelman, M.B., Parks, M. and Albrecht, T.L. (1987). 'Beyond close relationships: support in weak ties', in T.L. Albrecht and M.B. Adelman (eds) Communicating Social Support, Sage, London.

Anderson, E. (1990). Streetwise. Race, Class and Change in an Urban Community, University of Chicago Press, Chicago.

Argyle, M. (1994). Psychology and Social Class, Routledge, London.

Barrera, M. (1986). 'Distinctions between social support concepts, measures, and models', Journal of Community Psychology, 14, 413-445.

Bell, R.A., Leroy, J. and Stephenson, J.J. (1982). 'Evaluating the mediating effects of social support upon life events and depressive symptoms', Journal of Community Psychology, 10, 325-340.

Belle, D. (1983). 'The impact of poverty in social networks and support', Women and Health, 9 , 89-103.

Brand, S. and Hirsch, B. J. (1990). 'The contribution of social supports, workshift schedules, and the family life cycle to women's well being', in S. Duck (ed) Personal Relationships and Social Support, Sage, London.

Broadhead, W.E., Berton, B.H., James, S.A., Wagner, E.H. and Schoenbach, V.J. (1983). 'The epidemiologic evidence for a relationship between social support and health', American Journal of Epidemiology, 117, 521-537.

Bronfenbrenner, U., Moen, P. and Garbarino, J. (1984). 'Child, family, and community', in R.D. Parke (ed) The Family. Review of Child Development Research, vol. 7, University of Chicago Press, Chicago.

Cochran, M., Gunnarson, L., Grabe, S. and Lewis, J. (1990). 'The social supports of coupled mothers in four cultures', in M. Cochran (ed) Extending Families: The Social Supports of Parents and their Children, Cambridge University Press, Cambridge.

Cohen, S., Sherrod, D.R. and Clark, M.S. (1986). 'Social skills and the stress protective role of social support', Journal of Personality and Social Psychology, 50, 963-973.

Collins, M. and Pancoast, D. (1976). Natural helping networks, National Association of Social Workers, Washington DC.

Crenson, M.A. (1983). Neighbourhood Politics, Harvard University Press, Cambridge, MA.

DePaulo, B.M., Dull, W.R., Greenberg, J.M. and Swain, G.W. (1989). 'Are shy people reluctant to ask for help?', Journal of Personality and Social Psychology, 56, 834-844.

Eckenrode, J. (1983). 'The mobilization of social supports: some individual constraints', American Journal of Community Psychology, 11, 509-528.

Eckenrode, J. and Wethington, E. (1990). 'The process and outcome of mobilizing social support', in S. Duck (ed) Personal Relationships and Social Support, Sage, London.

Fisher, C. (1982). To Dwell Among Friends, Chicago University Press, Chicago.

Fisher, J.D., Nadler, A. and Whitcher-Alagna, S. (1982). 'Recipients reactions to aid', Psychological Bulletin, 91, 27-54.

Froland, C., Pancoast, D.L., Chapman, N.J. and Kimboko, P. (1981). 'Linking formal and 
informal support systems', in B.H. Gottlieb (ed) Social Networks and Social Support, Sage, London.

Garbarino, J. and Kostelny, K. (1993). 'Neighbourhood and community influences on parenting', in T. Luster and L. Okagaki (eds) Parenting: An Ecological Perspective, Lawrence Erlbaum Associates, Hillsdale, NJ.

Garbarino, J. and Sherman, D. (1980). 'High-risk neighbourhoods and high-risk families: the human ecology of child maltreatment', Child Development, 51, 188-198.

Gottlieb, B.H. (1985). 'Social support and the study of personal relationships', Journal of Social and Personal Relationships, 2, 351-375.

Granovetter, M. (1973). 'The strength of weak ties', American Journal of Sociology, 78, 1360-1380.

Hanson, B.S. and Östergren, P.O. (1987). 'Different social supports and social support characteristics, nervous problems and insomnia: theoretical and methodological aspects on some results from the population study "Men Born in 1914", Malmö, Sweden', Social Science and Medicine, 7, 849-859.

Harrison, P. (1983). Inside the Inner City, Penguin, Harmondsworth.

Hays, R.B. and Oxley, D. (1986). 'Social supports development and functioning during a life transition', Journal of Personality and Social Psychology, 50, 305-313.

Heller, K. and Swindle, R.W. (1983). 'Social support, perceived support, and coping with stress', in R.D. Felner, L.A. Jason, J. Moritsugu and S.S. Farber (eds) Preventive Psychology: Theory, Research and Practice in Community Intervention, Pergamon Press, New York.

Hobfoll, S.E. and London, P. (1986). 'The relationship of self-concept and social support to emotional distress among women during war', Journal of Social and Clinical Psychology, 4, 189-203.

House, J.S., Umberson, D. and Landis, K.R. (1988). 'Structures and Processes of Social Support', American Review of Sociology, 14, 293-318.

Jones, W.H. (1985). 'The psychology of loneliness: some personality issues in the study of social support', in I.G. Sarason and B.R. Sarason (eds) Social Support: Theory, Research and Application, Martinus Nijhoff, Dordrecht, the Netherlands.

Keller, S. (1968). The Urban Neighbourhood, Random House, New York.

Knox, P.L. (1989). 'The vulnerable, the disadvantaged, and the victimized: who they are and where they live', in D.T. Herbert and D.M. Smith (eds, Social problems and the city: new perspectives, Oxford University Press, Oxford.

Laireiter, A. and Baumann, U. (1992). "Network structures and support functions-theoretical and empirical analyses', in H.O.F. Veiel and U. Baumann (eds) The Meaning and Measurement of Social Support, Hemisphere, New York.

Laumann, E.O. (1973). Bonds of Pluralism: The Form and Substance of Urban Social Networks, Wiley, New York.

Lin, N., Dumin, M.Y. and Woelfel, M. (1986). 'Measuring community and network support', in N. Lin, A. Dean and W. Ensel (eds) Social Support, Life Events, and Depression, Academic Press, New York.

MORI (1982). Neighbours and Loneliness, Market Opinion and Research International, London.

Newcomb, M.D. (1990) 'Social support and personal characteristics: a developmental and interactional perspective', Journal of Social and Clinical Psychology, 9, 54-68.

Oakley, A. and Rajan, L. (1991). 'Social class and social support: the same or different?' Sociology, 25, 31-59.

Pacione, M. (1990). Urban Problems: An Applied Urban Analysis, Routledge, London.

Pearlin, L.I. (1985). 'Social structure and processes of social support', in S. Cohen and S.L. Syme (eds) Social Support and Health, Academic Press, New York.

Pearlin, L.I. and McCall, M.E. (1990). 'Occupational stress and marital support: a description of microprocesses', in J. Eckenrode and S. Gore (eds) Stress between work and family, Plenum, New York.

Rutter, M. and Quinton, D. (1977). 'Psychiatric disorder-ecological factors and concepts of causation', in H. McGurk (ed) Ecological Factors in Human Development, North-Holland, Amsterdam.

Rutter, M., Cox, A., Tupling, C., Berger, M. and Youle, W. (1975). 'Attainment and adjustment 
in two geographical areas. I. The prevalence of psychiatric disorder', British Journal of Psychiatry, 126, 493-509.

Sarason, B.R., Sarason, I.G., Hacker, T.A. and Bashman, R.B. (1985). 'Concomitants of social support: social skills, physical attractiveness, and gender', Journal of Personality and Social Psychology, 49, 469-480.

Stokes, J.P. (1985). 'The relation of social network and individual difference variables to loneliness', Journal of Personality and Social Psychology, 48, 981-990.

Thoits, P.A. (1982). 'Life stress, social support, and psychological vulnerability: epidemiological considerations', Journal of Community Psychology, 10, 341-362.

Tiejten, A.N. (1980). 'Integrating formal and informal support systems: the Swedish experience', in J. Garbarino and S.H. Stocking (eds) Protecting Children from Abuse and Neglect, JosseyBass, London.

Vaux, A. (1988). Social Support: Theory, Research and Intervention, Praeger, New York.

Vaux, A. (1990). 'An ecological approach to understanding and facilitating social support', Journal of Social and Personal Relationships, 7, 507-518.

Vaux, A. (1992). 'Assessment of social support', in H.O.F. Veiel and U. Baumann (eds) The Meaning and Measurement of Social Support, Hemisphere, New York.

Vaux, A., Burda, P., Jr. and Stewart, B. (1986). 'Orientation towards utilizing support resources', Journal of Community Psychology, 14, 159-170.

Veiel, H.O.F. and Baumann, U. (1992). 'The many meanings of social support', in H.O.F. Veiel and U. Baumann (eds) The Meaning and Measurement of Social Support, Hemisphere, New York.

Veroff, J., Douvan, E. and Kulka, R.A. (1981). The Inner American, Basic Books, New York. Willmott, P. (1986). Social Supports Informal Care and Public Policy, Policy Studies Institute, London.

Willmott, P. (1987). Friendship supports and social support, Policy Studies Institute, London.

Wilkinson, L. (1986). The System for Statistics, Systat, Inc., Evanston, IL.

Young, M. and Willmott, P. (1973). The Symmetrical Family, Routledge, London. 